\title{
Contradiscurso del Anti-Humboldt al Tratado de Libre Comercio de América del Norte
}

\author{
Anti Humboldt's Counter-discourse \\ to the North American Free Trade Agreement
}

\author{
ISAAC MAGaña GCANTÓN \\ Harvard University \\ maganagcanton@g.harvard.edu
}

RESUMEN: En este trabajo se analizan cinco fragmentos del Tratado de Libre Comercio de América del Norte (TLCAN) que han sido intervenidos por Hugo García Manríquez en Anti-Humboldt a través de un trabajo de borraduras y superposiciones al documento original, que subyacen en el libro como una marca de agua de color gris pálido. La propuesta es leer el documento original en conjunto con las palabras seleccionadas por García Manríquez para de ese modo extraer un sentido que desafía las regulaciones migratorias, cada vez más endurecidas, en la frontera México-Estados Unidos. En esa dirección, lo que se produce es un contradiscurso que pugna por la apertura territorial y la despenalización del cruce fronterizo. Se trata, pues, de una propuesta transversal que pone en evidencia la ideología segregacionista oculta tras las proclamas de libertad y armonía del tratado.

\author{
PALABRAS Clave: \\ políticas migratorias; \\ Anti-Humboldt; \\ poesía; \\ frontera México-Estados Unidos; \\ Hugo García Manríquez.
}

KEYWORDS:

Migration Policies; Anti-Humboldt;

Poetry;

United States-Mexico Border; Hugo García Manríquez.

ABSTRACT: This paper analyzes five excerpts from the North American Free Trade Agreement (NAFTA) that have been subjected to intervention, through a work of erasures and overlays to the original document, which appear in the intervention as a mellow-grey watermark, in Hugo García Manríquez's Anti-Humboldt. This article aims to read the original document along with the bold words selected by the author in order to extract a sense that challenges the increasingly tightened migration policies on the United States-Mexico border. What this approach produces is a counter-discourse that proclaims for the territorial opening and the decriminalization of the border crossing. This work thus presents an oblique proposal which highlights the 
segregationist ideology hidden behind the proclamations of freedom and harmony of the agreement.

recepción: 19 agosto 2018

aceptación: 27 octubre 2018

La entrada en vigencia del Tratado de Libre Comercio de América del Norte (TLCAN o NAFTA, por sus siglas en inglés) en 1994 marca un momento importante en las relaciones entre México y Estados Unidos. La era del TLCAN ha sido, entre los países involucrados, una etapa de aproximación y distanciamiento. Si bien desde entonces el intercambio comercial se ha intensificado gracias a la apertura de las políticas mercantiles, alcanzando los niveles más altos en la historia de la relación entre estos países -muy en especial entre México y Estados Unidos (Hollifield y Osang: 329-335) —, es de igual modo cierto que, desde la firma del tratado, las políticas migratorias en la frontera México-Estados Unidos se han endurecido de un modo progresivo e intensificado (Massey, Durand y Malone: 48-49). La paradoja de esta relación de apertura y cierre se ve retratada en el hecho de que a los pocos meses de que el TLCAN comenzara a funcionar entró en vigor la Operación Gatekeeper, uno de los esfuerzos más sobresalientes de la Patrulla Fronteriza de los Estados Unidos por detener los flujos de migración de México a los Estados Unidos. ${ }^{1}$ Desde entonces, con el fin de entender la compleja relación entre ambos países que se desprende a partir de la firma del TLCAN, muchos libros y artículos han sido publicados. De igual modo, muchas intervenciones artísticas han sucedido en

1 De un modo general, la Operación Gatekeeper consistió en bloquear el flujo de migrantes indocumentados en los corredores preferenciales, aquellos puntos fronterizos que registraban el mayor tránsito de personas. Consecuencia de esto, el flujo de indocumentados se desplazó más allá de las áreas metropolitanas donde los riesgos para cruzar la frontera eran mucho mayores. Y aunque la idea detrás del cierre de los corredores preferenciales era desalentar el cruce de indocumentados, lo que en realidad se promovió con esta operación fue la profesionalización de los contrabandistas que ayudan a los indocumentados en el cruce — popularmente conocidos como polleros- al tiempo que se multiplicó el riesgo del cruce de la frontera y, por tanto, también la mortandad en ésta (Hing: 126-144). Para un análisis más amplio de los antecedentes, las políticas detrás de la Operación Gatekeeper y los resultados que tuvo véase Hing 2001 y Nevins 2002. 
ambos lados de la frontera (cfr. Candida 2012 y Yúdice 2003). En este contexto y en el medio de estas producciones es que el Anti-Humboldt de Hugo García Manríquez fue publicado en el vigésimo aniversario de la puesta en marcha del tratado, en 2014. ${ }^{2}$

La singularidad del Anti-Humboldt, y la razón por la cual este trabajo se centra en el análisis de algunos de sus fragmentos, descansa en los modos en los que García Manríquez desafía el silencio guardado por el TLCAN a propósito de las políticas migratorias, las consecuencias de la apertura del mercado mexicano inaugurada con la entrada en vigor de este tratado y las incontables muertes acontecidas en la frontera México-Estados Unidos. He dicho modos de desafiar, algo que se relaciona inevitablemente con la forma misma del texto, con su materialidad. En esta intervención, García Manríquez ha seleccionado algunos fragmentos del TLCAN y los ha reproducido, tal cual aparecen en el documento oficial — respetando el tipo y tamaño de letra, inclusive-, en las páginas de su libro como una marca de agua de color gris pálido. A continuación ha resaltado en negro frases, palabras y signos de puntuación con el fin de llamar la atención sobre aquellos detalles que resultan importantes en su lectura. El resultado es un palimpsesto: los fragmentos atenuados con la marca de agua permanecen legibles, pero son las palabras ennegrecidas las que atraen de primer momento la mirada. Visualmente estas palabras parecen islas en un mar de lenguaje, un conjunto de constelaciones. Estas constelaciones, que bien pueden ser leídas como poemas conceptuales, tienen la característica de ser resistentes a la construcción de sentido, al menos de una manera in-

2 El título del texto presenta una interesante tensión. Si pensamos la intervención de García Manríquez contra Humboldt (Alexander), entonces el título parece preciso, una intervención que busca desorganizar y releer las clasificaciones y las nomenclaturas, lo perfectamente ordenado, de lo que el TLCAN es un importante ejemplo; en otras palabras, al apostar por el caos y el libre flujo de personas y mercancías en un espacio desterritorializado, García Manríquez está leyendo contra el espíritu de Alexander von Humboldt, de allá Anti-Humboldt; por otro lado, sin embargo, si pensamos en Wilhelm von Humboldt, su hermano, quien en sus escritos lingüísticos afirmó que el lenguaje no era una taxonomía, sino un mundo, entonces Anti-Humboldt es un título poco afortunado e impreciso, pues más bien la intervención se estaría ajustando a la línea de pensamiento y al tren de reflexión de Wilhelm von Humboldt en el que las leyes, las nomenclaturas y las descripciones resultan demasiado bastas y líquidas para la aprehensión y la captura. 
mediata. Esto se debe a que la sintaxis no es convencional y sacar sentido de los conjuntos reclama de menos el doble de esfuerzo que nos requiere leer una frase compuesta de un modo tradicional.

Dicho lo anterior, la propuesta de este trabajo es la siguiente: en un tiempo en el que por lo regular las formas y las experiencias del lenguaje son apropiadas muy fácil y casi inmediatamente por los sistemas capitalistas para el puro consumo y subjetivación (Padilla: 15-20) y en el que el lenguaje hermético e infranqueable es a menudo fetichizado por snobs y los mismos sistemas capitalistas que lo vuelven una forma de capital cultural y simbólico que perpetúa relaciones de inequidad (Bourdieu: 3-4), conviene hacer una revisión de la intervención de García Manríquez como un elemento que se resiste a ambos extremos y se sitúa justo en el medio: un espacio incómodo donde el sentido no es transparente ni inmediato, pero que tampoco resulta absolutamente ilegible. Como ya he sugerido más arriba, a través de una lectura cuidadosa del Anti-Humboldt es posible friccionar las palabras y sacar sentido de ellas, un sentido que apunta a una lectura a contrapelo del TLCAN. La hipótesis de este texto es que lo que emerge de este ejercicio es un borramiento de las fronteras entre los países participantes del tratado — puestas en explícito al interior del documento- y una denuncia de las políticas migratorias de los Estados Unidos que marginalizan y amenazan de muerte a los cientos de migrantes que cada día intentan cruzar "al otro lado" (una preocupación más que urgente en el presente desde el cual este trabajo se escribe). Dicho de otro modo: la siguiente lectura propone trabajar con el TLCAN y con el poema al mismo nivel; es decir, las intenciones de estas pesquisas son no perder de vista lo que permanece en el texto como marca de agua, que es el documento legal tal como fue concebido, y leer lo destacado en negritas en relación con sus directrices y cláusulas. Entretanto, los pasajes a los que nos referiremos son sólo aquellos que establecen las condiciones del flujo de personas en los límites territoriales de las fronteras. Finalmente, Ilamo la atención sobre el hecho de que la lectura de los fragmentos no es lineal, pues, a diferencia de lo que se podría pensar, la extracción de sentido de este texto no responde mejor a una lectura teleológica, sino que es una lectura rizomática lo que ha de permitirnos alcanzar nuestra interpretación última. 
Ahora bien, a sabiendas de que existe una vasta bibliografía crítica y especializada sobre el TLCAN desde las ciencias sociales, ¿qué sentido tiene hacer una revisión de la intervención poética que hace García Manríquez al documento? Si partimos del supuesto de que sobre las cláusulas de este tratado descansan las pautas de flujo e intercambio, tanto humano como comercial, entre el espacio territorial que comprenden las fronteras políticas de México, Estados Unidos y Canadá, ${ }^{3}$ intervenirlo significa alterar el sustento ideológico que rige las relaciones de estos países, en especial —en las miras de este trabajo — aquella que se juega en los límites geográficos de México y Estados Unidos. García Manríquez emplea las propias palabras del tratado para crear un contradiscurso que opera contra la xenofobia y las políticas migratorias ocultas, diluidas y silenciadas en el discurso del tratado permitiendo imaginar un sustrato y una realidad distintos. En otras palabras, la aproximación al tratado por parte de García Manríquez echa luz sobre las injustas condiciones bajo las que opera la frontera México-Estados Unidos, así como también la ideología que ampara al tratado. Por tanto, a través de una lectura que preste atención a la retórica del TLCAN y la operación poética de García Manríquez en el mismo nivel es posible desenmascarar las intenciones escondidas detrás de las elocuentes frases "Reafimar los lazos especiales de amistad", "Contribuir al desarrollo armónico", "Crear nuevas oportunidades de empleo, mejorar las condiciones laborales", "Proteger, fortalecer y hacer efectivos los derechos fundamentales de sus trabajadores", etcétera, que son enunciadas en el "Preámbulo" del TLCAN como objetivos principales.

Tal como es formulado por José Ignacio Padilla, en el lenguaje se juega el modo en el que nos relacionamos con el mundo. Por tanto, la experiencia poética a la que invita el poema viene a ser un enclave de resistencia y acción contra las formas discursivas perfectamente ordenadas, un modo de releer la organización lingüística a primera vista transparente para desentrañar y argumentar contra lo no dicho, contra el sentido que se esconde detrás de la claridad y el orden. Escribe así, Padilla, en EI

3 Las relaciones espaciales se vuelven cruciales en tanto que el flujo de gente y bienes, así como el intercambio de información y servicios, requieren una inversión de dinero, tiempo y energía física a través de los cuales se vuelve posible lidiar con las dificultades de la distancia y la hostilidad del mismo espacio (Harvey: 126). 
terreno en disputa es el lenguaje: "Lo propio de la experiencia poética es propiciar el choque entre el uso discursivo que nos sirve para in-formar el magma de nuestra vida y la resistencia 'material' del lenguaje mismo a la significación. En un mundo donde todo tiene nombre y donde todo está categorizado, clasificado, cuantificado" (90). En un mundo que tiende a la legibilidad, a la clasificación y al orden —y aquí el TLCAN es un ejemplo modélico con sus cláusulas y definiciones infinitas metódicamente organizadas — vale la pena proponer un mundo caótico que se resista a la legibilidad inmediata y a la velocidad, que proponga un extrañamiento áspero que obligue al lector a detenerse y pensar en lo que se está (re)formulando, lo que está cambiando en el discurso, lo que se está cuestionando, sobre lo que se está echando luz. Al mismo tiempo hay la invitación a realizar un esfuerzo por recuperar visualmente las palabras que aparecen dispersas en la página, de reconocer aquellas que han sido resaltadas en negro de las que aparecen en ese gris pálido que es la marca de agua.

Pero vayamos al texto, que a través de mirarlo podemos aterrizar mejor lo que he señalado más arriba. Aquí también merece la pena señalar que cada vez que se citen los fragmentos del Anti-Humboldt éstos aparecerán siempre, también, como una imagen, fotografía del original, ya que citar la intervención con precisión visual resulta indispensable para comprender la dimensión material a la que he hecho ya alusión en los primeros párrafos de este artículo. Y ahora sí, volvamos a lo que nos ocupa: el fragmento a continuación (García Manríquez: 72) se encuentra justo hacia el final del Anti-Humboldt y se refiere a los límites de inversión extranjera y capital autorizados en el territorio mexicano:

3. Con el fin de permitir una administración adecuada de los límites de capital señalados en esta Sección, aplicarán las disposiciones siguientes:

(a) cada filial financiera extranjera tendrá un capital autorizado determinado por México, y el capital pagado dicha institución no deberá ser menor que aquel autorizado al momento de la aprobación de su establecimiento. vez establecida, México podrá permitir que el capital autorizado exceda al capital pagado. El capital autorizado se reducirá, por ninguna medida de México (salvo por medidas prudenciales), por debajo del capital pagado. importe máximo de las operaciones de cada filial financiera extranjera se determinará, sobre la base de tra nacional, en función del monto que resulte menor entre su capital y su capital autorizado.

(b) México se reserva el derecho a imponer limitaciones a la transferencia de activos o pasivos de filiales financier extranjeras que tengan el efecto de evadir los límites de capital señalados en esta lista. Este inciso no se aplica a transferencias de fondos de buena fe para constituir depósitos de una noche, ni a otras transferencias de buena f pasivos bancarios. 
Aquí, García Manríquez le da la vuelta a las palabras del tratado que pretenden servir como regulación e instrucción de la circulación de capitales. Entonces dice: "los límites / un capital / el capital / el capital / al capital / por debajo del capital / evadir los límites de capital / una noche". Las intenciones de la intervención que propone el Anti-Humboldt en este fragmento son, pues, las de producir un dislocamiento al sentido original. La selección final - "evadir los límites de capital / una noche" — nos está dando una de las posibles claves de lectura, que es la de las vanguardias clásicas, que es la de Viktor Shklovsky cuando dice en "Art as Technique": "Al examinar el lenguaje poético [...] percibimos que el carácter estético se revela siempre por los mismos signos. Está creado conscientemente para liberar la percepción del automatismo. Su visión representa la finalidad del creador y está construida de manera artificial para que la percepción se detenga en ella y llegue al máximo de su fuerza y duración" (68-69). De la cita de Shklovsky me interesa destacar el binomio "percepción libre del automatismo / percepción con la máxima fuerza y duración" porque a mi entender es ésa la intención de García Manríquez cuando extrae del tratado la idea de evadir los límites del capital por una noche. Esa evasión que es crítica en tanto que está emitiendo un juicio explícito sobre las intenciones señaladas por el TLCAN de regular los flujos de capital sólo es posible en tanto que se lleve a cabo una lectura lenta y concienzuda del tratado que troque lo automático (automático aquí entendido como velocidad e inconsciencia) por lo pausado y reflexivo. Una petición del autor a los lectores del Anti-Humboldt a no dar por sentado los presupuestos, pensar en ellos nuevamente, reñirlos: "contra el fondo 'translúcido', escasas palabras como espectros atormentando el documento del que son parte, constituyendo su doble" (García Manríquez: 78).

Entretanto, la insistencia en cierto lenguaje administrativo a través del cual el documento legal busca la claridad y la precisión en sus definiciones es convertido en este pasaje - aunque es en general una constante en la intervención de García Manríquez al TLCAN-, a través de la intervención poética, en una repetición anafórica que remite a ciertas formas del lenguaje religioso, a la oración, cuya función resulta ajena y escapa a las impuestas por las lógicas del capital; "evadir los límites del capital / una noche" a través de una intervención desde la poesía que llama la atención 
sobre un funcionamiento religioso puede ser leído como un modo de insistir en la función práctica e instrumental que puede tener la poesía para intervenir de manera específica y concreta en las cuestiones del Estado. En el caso del Anti-Humboldt, habilitando una lectura del documento que hace hincapié y señala ciertos aspectos de su ideología que de otro modo permanecerían ocultos.

En las primeras páginas del Anti-Humboldt, García Manríquez realiza una intervención de tono transfronterizo que, de algún modo, por metonimia define también la totalidad del poema —no como única lectura, ojo, sino como una más que es plausible- La marca de agua es una descripción muy detallada sobre lo que se entiende por territorio y, a su vez, una enumeración de los límites geográficos de los tres países involucrados en el TLCAN. Cito un fragmento (García Manríquez: 16) para aterrizar lo que estoy pensando: "territorio significa: ii) las islas, incluidos los arrecifes y cayos en los mares adyacentes; iii) las islas de Guadalupe y las de Revillagigedo, situadas en el Océano Pacífico". La enumeración sigue hasta terminar de enmarcar las fronteras políticas de México, Estados Unidos y Canadá. De nuevo y en otras palabras: este fragmento habla sobre lindes, divisiones y márgenes. Lo que hace García Manríquez con él es leerlo a contrapelo y abrir las fronteras dentro del poema, dentro del discurso, dándole un sentido total a la palabra más Ilamativa del tratado: Libre. Entonces el autor destaca de ese pasaje lo siguiente: "territorio significa / las islas, / los zócalos marinos / los / interiores; / el espacio situado / toda zona más allá México dentro de México / más allá toda zona / derechos sobre el fondo / que incluye los cincuenta estados / las zonas libres / toda zona más allá de los mares". Contra el claro y transparente decreto fronterizo de qué le "pertenece" a cada país, dónde empieza y termina la frontera de cada uno, las palabras emergentes reaccionan diciendo: un momento, aquí territorio no termina en tal o cual frontera política, sino que es "toda zona más allá, toda zona más allá de los mares"; o sea es indefinida y, desde cierto punto de vista, infinita: 
territorio significa:

(ii) las islas, incluidos los arrecifes y cayos en los mares adyacentes;

(iii) las islas de Guadalupe y las de Revillagigedo, situadas en el Océano Pacífico;

(iv) la plataforma continental y los zócalos submarinos de las islas, cayos y arrecifes;

(v) las aguas de los mares territoriales, en la extensión y términos que fije el derecho internacional, las aguas marítimas interiores;

(vi) el espacio situado sobre el territorio nacional, con la extensión y modalidades que establece el propio derecho internacional; $y$

(vii) toda zona más allá de los mares territoriales de México dentro de la cual México pueda ejercer derechos sobre el fondo y el subsuelo marinos y sobre los recursos naturales que éstos contengan, de conformidad con el derecho internacional, incluida la Convención de las Naciones Unidas sobre Derecho del Mar, así como con su legislación interna;

(b) respecto a Canadá, el territorio en que se aplique su legislación aduanera, incluida toda zona más allá de los mares territoriales de Canadá dentro de la cual, de conformidad con el derecho internacional y con su legislación interna, Canadá pueda ejercer derechos sobre el fondo y subsuelo marinos y sobre los recursos naturales que estos contengan; y

(c) respecto a Estados Unidos:

(i) el territorio aduanero de Estados Unidos, que incluye los cincuenta estados, el Distrito de Columbia y Puerto Rico;

(ii) las zonas libres ubicadas en Estados Unidos y en Puerto Rico; y

(iii) toda zona más allá de los mares territoriales de Estados Unidos dentro de la cual, de conformidad con el derecho internacional y con su legislación interna, Estados Unidos pueda ejercer derechos sobre el fondo y subsuelo marinos y sobre los recursos naturales que éstos contengan.

Este fragmento es, quizá, uno de los más transparentes en tanto construcción de sentido, pero sin embargo conserva aquello que Padilla describe como el movimiento que se resiste a la significación y que interrumpe la discursividad del texto para producir con lo anterior una enunciación distinta. Las frases del documento legal abandonan su sentido inicial, resistiéndose a la estandarización, y "prepara[n] el camino para nuevas significaciones" (Padilla: 79). De ese modo, el significado inicial de este pasaje que legisla los contornos territoriales es invertido y entonces pasa a ser una intervención de apertura y continuidad territorial, una desorganización de las demarcaciones espaciales del tratado. Una desterritorialización y una reterritorialización productos de un mismo movimiento.

El ejercicio retórico, por otra parte, va acompañado de una intervención material: es posible y, tanto más, pertinente leer este fragmento como paisaje. Las frases perfectamente ordenadas, de comunicación asertiva, distribuidas en claros incisos y en párrafos justificados se ven desordenados por esas palabras que prevalecen, por su color, en lo visual, más que las otras. Las palabras resaltadas en negro salpicadas en la página —islas flotantes en un mar de lenguaje - sin un aparente patrón de selección provocan dentro de ese orden descriptivo y discursivo un efecto contrario 
a lo que enuncia el documento legal. García Manríquez desordena el paisaje, las palabras, cuestionando de igual modo el discurso (ya hemos visto que el sentido que se puede extraer de la selección de palabras es justo el contrario al enunciado originalmente en el documento legal) fijado en las páginas del TLCAN. "Resistencia material", diría Padilla.

Muy en diálogo con este fragmento, García Manríquez (70) interviene también uno que se refiere a los servicios transfronterizos, específicamente las telecomunicaciones y radiocomunicaciones. En una de las secciones del TLCAN leemos: "Canadá se reserva el derecho de adoptar o mantener cualquier medida respecto a la radiocomunicación [...] y servicios de telecomunicación. [...] Estas medidas se aplican a asuntos tales como [...] asignación del espectro, [...] interconexión entre redes y servicios y requisitos de enrutamiento que impiden la prestación de manera transfronteriza de redes de telecomunicaciones". En negritas, García Manríquez destaca lo siguiente: "asignación del espectro / de manera transfronteriza" (70). Frente a la reserva de derecho que se hace el documento — que en otras palabras se refiere a la unidireccionalidad de las decisiones sobre, en este caso, las telecomunicaciones y radiocomunicaciones-, lo que queda destacado es una apertura del espectro. Una vez más: las fronteras quedan abiertas para el libre flujo, para el tránsito transfronterizo. Es decir, mientras las cláusulas legales del TLCAN señalan una circulación condicionada y modulada a discreción, la operación puesta en este fragmento del Anti-Humboldt es la de leer a contrapelo y proponer lo contrario al documento que interviene. Contra las regulaciones, asignar los espectros más allá de las fronteras:

\footnotetext{
Servicios Transfronterizos

Canadá se reserva el derecho de adoptar o mantener cualquier medida respecto a la radiocomunicación, los cables submarinos y la prestación de redes de telecomunicaciones y servicios de telecomunicaciones. Estas medidas se aplican a asuntos tales como entrada al mercado, asignación del espectro, tarifas, acuerdos entre los portadores, términos y condiciones del servicio, interconexión entre redes y servicios y requisitos de enrutamiento que impiden la prestación de manera transfronteriza de redes de telecomunicaciones y de
}

Los "espectros" del poema pueden ser leídos también, aquí, como aquellas voces que emergen del documento, que se resisten a desaparecer entre la acumulación del lenguaje administrativo. Los espectros, pues, 
como las voces oprimidas - ya de cuerpos muertos, ya de cuerpos silenciados u olvidados - por las políticas y las regulaciones del tratado que a través del ejercicio poético reaparecen para transitar el paisaje de "manera transfronteriza", en el territorio reorganizado y repensado para ser hospitalario, y cuyo territorio es "toda zona más allá de los mares".

Desde el artículo 406 y hasta el artículo 412, el TLCAN establece cuáles son las condiciones para distinguir entre materiales y bienes originarios y no originarios. En un sentido económico, la distinción es relevante en tanto que a partir de ella se determina la tasa arancelaria de los productos que circulan a través de las tres fronteras. No obstante, la distinción simbólica resulta, en este caso, más importante: a pesar de que en términos fácticos el TLCAN es un documento para la libre circulación de mercancías a lo largo del espacio comprendido por los tres países, lo que surge de la lectura de estos siete artículos es más bien una atenuación del significado de libertad. Distinguir entre materiales y bienes originarios y no originarios es, finalmente, discriminar. Y el trato especial, el trato diferente, ¿no es, acaso, uno de los temas más sensibles — digámoslo así, problemáticos- en los espacios fronterizos y, muy especialmente, en la frontera México-Estados Unidos? Es en esa dirección que García Manríquez atiende, en este fragmento, la urgencia. Los fragmentos a los que nos hemos referido anteriormente se ocupan de cuestiones territoriales y fronterizas; éste en cambio trabaja sobre los flujos humanos a lo largo de la frontera México-Estados Unidos: "originario / originarios y no originarios / cuando originarios y no originarios se mezclen bajo una misma forma / como originarios sin tomar en cuenta el lugar de su producción / la simple dilución en agua o en otra sustancia / su objetivo es evadir este capítulo / este capítulo es el Sistema Armonizado; / dos o más hilos o / todos los hilos las fibras". La intervención de este pasaje, por ese camino, resulta relevante en tanto que, como hemos dicho, García Manríquez (36) tematiza a través del documento legal una de las cuestiones más problemáticas de la frontera, el tránsito humano de las personas nacidas en territorio estadounidense y las nacidas fuera de él. Entonces, una lectura posible, que no exclusiva, de este fragmento es leer 
"originarios y no originarios" como "nacidos en o nacidos fuera de", del mismo modo que "lugar de su producción" se puede leer como "lugar de nacimiento". Así, el sentido de este pasaje del documento legal se vuelve, a través de este ejercicio de relectura, contra las regulaciones migratorias que operan en la frontera México-Estados Unidos, poniendo el dedo y operando contra lo evidente, pero silenciado a lo largo de todo el TLCAN: las limitaciones y opresión que enfrentan los migrantes, cuyo estatus no es el de ciudadanos, la falta de derechos de los nacidos fuera del territorio estadounidense. Al respecto, refiriéndose a la condición de los refugiados, Giorgio Agamben escribe: "En el sistema del Estado-nación los pretendidos derechos sagrados e inalienables del hombre aparecen desprovistos de cualquier tutela y de cualquier realidad desde el momento mismo en que deja de ser posible configurarlos como derechos de los ciudadanos de un Estado" (161). La intervención de García Manríquez permite imaginar una realidad distinta en la que los derechos de los individuos dentro de un territorio específico no están determinados por su condición de ciudadanía, reclama una hospitalidad absoluta. En la intervención de García Manríquez originarios y no originarios se mezclan bajo una misma forma; es decir que, desde esta perspectiva, su reclamo se alinea con aquello que Jacques Derrida Ilama el arrivant absoluto: "el arrivant absoluto todavía no tiene nombre ni identidad. No es un invasor ni un ocupante, tampoco es un colonizador, aunque también podría convertirse en uno. [...] Puesto que el arrivant absoluto todavía no tiene identidad, su lugar de llegada se encuentra también sin identificar: todavía no se sabe o ya no se sabe cómo nombrar, cuál es el país, el lugar, la nación, la familia, la lengua, el 'en casa' que acoge al arrivant absoluto" (63-64).

En esa dirección, también, conviene mencionar que el Sistema Armonizado es, según la Comisión Económica de las Naciones Unidas, una nomenclatura válida para el intercambio de productos e información en el comercio internacional. Una nomenclatura que al final de cuentas segrega y homogeneiza en proporciones más o menos iguales: permite el tránsito global al tiempo que "describe", "clasifica" y "codifica". La intervención de García Manríquez invierte las intenciones de los artículos del TLCAN y propone que "lo originario y lo no originario se mezclen bajo una misma forma y sin distinción"; y aún más: evadiendo las intenciones del capítulo 


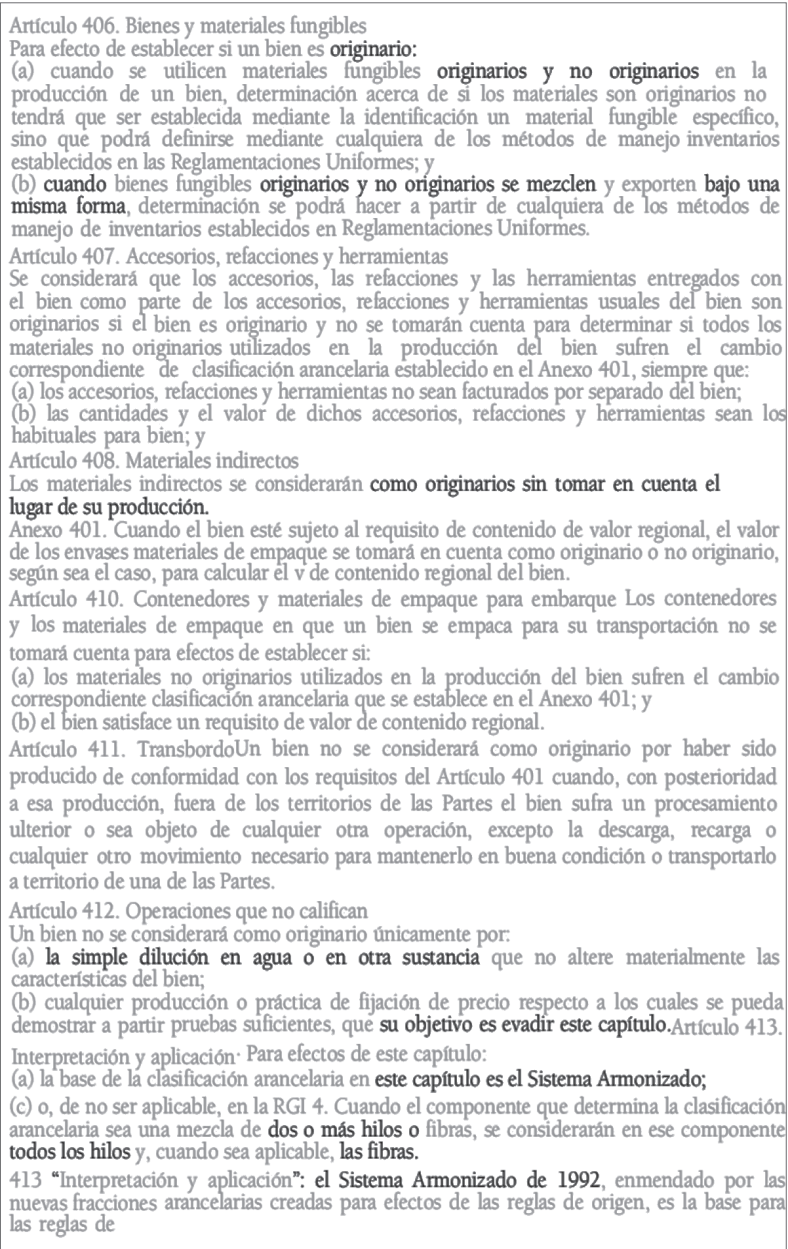

que son justamente las de separar y discriminar, moldear, para entonces —sólo entonces_-, interviniendo las palabras que en el documento legal arrinconan y dividen, construir frases cuyo sentido evocan el "libre" tránsito, sin distinción, a lo largo de las fronteras de cada una de las partes involucradas en el tratado, imaginando la abolición de los límites impuestos por la definición misma de estado-nación. ${ }^{4}$

4 Del modo en el que lo define la UNESCO, "The nation-state is an area where the cultural boundaries match up with the political boundaries. The ideal of 'nation-state' 
El último pasaje que me propongo leer es sólo un fragmento de la interminable lista de fracciones arancelarias correspondientes a los productos mexicanos que cruzan la frontera. Como comenté más arriba, en el Sistema Armonizado los productos deben tener un código con validez internacional que autorice el tránsito de mercancías. Todo está considerado y catalogado cuidadosamente en esta sección del TLCAN: quesos, lácteos, carnes frías, animales vivos, alimentos procesados, frutas, verduras y un largo etcétera. La intervención de García Manríquez (45) a esta lista resulta en una puesta en evidencia de la situación de los migrantes que intentan atravesar el borde entre México y Estados Unidos:

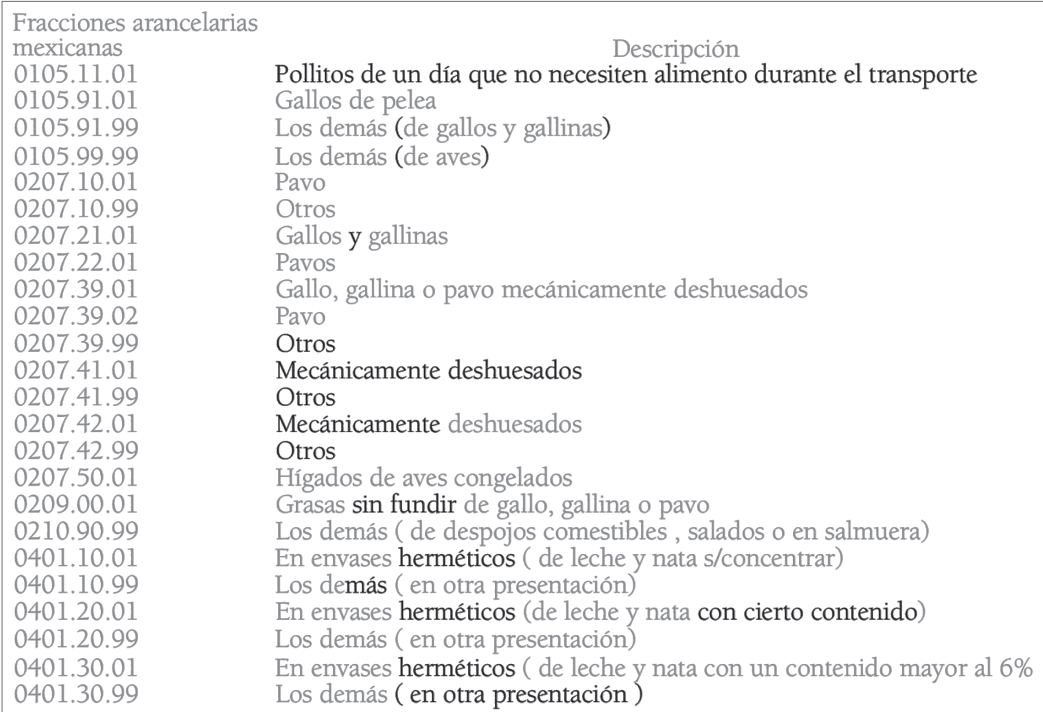

Quizá no hace falta decirlo, pero de todos modos lo explicito: un poIlero es la persona encargada de transportar indocumentados a los Estados Unidos. En esa dirección, los "pollitos de un día que no necesitan alimen-

is that the state incorporates people of a single ethnic stock and cultural traditions" ("Nation-State") ["La nación-estado es un área donde las fronteras culturales coinciden con las fronteras políticas. El ideal de 'nación-estado' es que el Estado incorpore gente de un mismo origen étnico y tradiciones culturales" (trad. del autor)]. 
to durante el transporte" destacados en negritas por García Manríquez — que son apenas un código en el documento legal: 0105.11.01- pueden ser leídos como aquellas personas que son transportadas, regularmente en camiones o camionetas, por los contrabandistas - polleros - al otro lado de la frontera, y que como ha sido ya ampliamente documentado y reportado, tanto en medios masivos como especializados, suelen recibir tratos severos, entre los que se encuentra, por ejemplo, la privación de agua y alimentos; naturalmente, a causa de este trato y las condiciones del cruce impuestas por las políticas migratorias, algunos migrantes mueren en el camino, pasando a formar parte de la cifra de cuerpos que muchas veces no son encontrados o reclamados. Algo que hace eco con otra de las selecciones de García Manríquez: "Otros / Mecánicamente deshuesados / Otros [...] / herméticos / (en otra presentación)". ${ }^{5}$ Lo "mecánicamente deshuesado", lo "hermético", la "otra presentación" evoca fuertemente - aunque no de modo exclusivo - esa condición de muertos anónimos en el desierto en la que muchos devienen durante el cruce. García Manríquez toma la oportunidad de las nomenclaturas del tratado, las cláusulas que pretenden tener control y conteo de todas las cosas que atraviesan el borde, para lanzar una crítica contra lo inhumano en las condiciones del cruce y lo que se vuelve incontable en el espacio que media entre las áreas urbanas de México y las poblaciones estadounidenses más próximas a la línea fronteriza. Finalmente, condiciones que descansan en el sustrato ideológico del documento que establece las pautas de lo que "entra" y "no

5 De acuerdo con el artículo "Deaths in the Desert: The Human Rights Crisis on the U.S.-Mexican Border", entre 1994 (fecha en la que entra el vigor el TLCAN) y 2009, debido al endurecimiento de las medidas migratorias en la frontera entre México y Estados Unidos, poco más de 5,000 migrantes murieron en el desierto de Sonora intentando cruzar a los Estados Unidos (Androff: 165). Entretanto, el artículo "Is it worth risking your life?: Ethnography, risk and death on the U.S.-Mexico border" señala que entre las principales causas de muerte en la frontera se encuentra la deshidratación e insolación, mientras que otros mueren por accidentes automovilísticos o violencia directa; el autor comenta con elocuencia una realidad que urge atender: "There are Mexican and American assailants and kidnappers after their money; heat, sun, snakes and cacti after their bodies; armed American vigilantes after their freedom; and Border Patrol agents after their records" (Holmes: 153) ["Hay asaltantes y secuestradores tanto mexicanos como estadounidenses en busca de su dinero; calor, sol, cactus y serpientes tras sus cuerpos; vigilantes estadounidenses armados persiguiendo su libertad; finalmente, agentes de la patrulla fronteriza siguiéndoles los pasos" (trad. del autor)]. 
entra" — de la circulación al fin-y que, al mismo tiempo, no se posiciona sobre la situación del migrante que intenta atravesar el borde que media entre México y Estados Unidos, ejerciendo así una opresión silenciosa y brutal.

A través de este recorrido he mostrado cinco de los varios fragmentos intervenidos por García Manríquez que dialogan con temas migratorios (fronteras políticas, políticas migratorias y el cruce de migrantes). A través de estas intervenciones - a ratos reacias a la sintaxis, a ratos al sentidoel sustrato ideológico oculto en la base del TLCAN se ve evidenciado y cuestionado, dando paso a la reflexión y al desafío de sus estatutos. "Los restos ilegibles" de esas "formas provisionales" — por usar la terminología acuñada por Padilla — sobre las que trabaja García Manríquez piden ser leídos de una manera lenta (es decir, de manera simultánea y comparada con la marca de agua) que friccione y ponga en diálogo los dos sentidos del documento: lo decretado por las autoridades firmantes y las palabras destacadas en negro que han sido recombinadas para resistir a la opresión que ejerce el lenguaje del tratado — pero también, en general, las políticas migratorias de Estados Unidos-sobre los migrantes. Huelga decir que, por esta vía, la poesía extraída del discurso del TLCAN no sólo se resiste en tanto forma, sino que al construir su sentido en contra de las declaraciones originales del tratado pone en evidencia la ideología oculta detrás de la organización del lenguaje en el documento. Es decir, la poesía se vuelve una herramienta para leer las intenciones veladas, denunciar la ideología que sustentan el TLCAN.

\section{Bibliografía}

Agamben, Giorgio. Homo Sacer I. El poder soberano y la nuda vida. Antonio Gimeno Cuspinera (trad.) Valencia: Pre-textos, 2006.

ANDROFF, DAVID K. y Y. KYOKO. "Deaths in the desert: the humans rights crisis on the U.S.-Mexico border", en Social Work, 57-2 (abril de 2012): 165-173.

Bourdieu, Pierre. "Les trois ētats du capital culturel", en Actes de la Recherche en Sciences Sociales, 30-1 (1979): 3-6. 
CAndida Smith, Richard. "Contemporary Art Along the U.S.-Mexican Border", en The Modern Moves West. Philadelphia: Philadelphia University Press, 2012. 182-207.

Derrida, Jacques. Aporias. Morir - esperarse (en) los "límites de la verdad". Cristina de Peretti (trad.). Barcelona: Paidós, 1998.

García Manríquez, Hugo. Anti-Humboldt. Una lectura del Tratado de Libre Comercio de América del Norte. México / Nueva York: Aldus / Litmus, 2014.

Harvey, David. "Space as a key word", en Spaces of Global Capitalism. Londres / Nueva York: Verso, 2006. 117-148.

HING, BILl ONG, "The Dark Side of Operation Gatekeeper", en U.C. Davis Journal of International Law and Policy, 7-2 (primavera de 2001): 121-223.

Hollifield, James y Thomas Osang, "Trade and Migration in North America: The Role of NAFTA", en Law and Business Review of the Americas, 11-3 (verano de 2005): 327-360.

Holmes, Seth M. "'Is it worth risking your life?': Ethnography, risk and death on the U.S.-Mexico border", en Social Science \& Medicine, 99 (diciembre de 2013): 153-161.

Massey, Douglas S., Jorge Durand y Nolan J. Malone, "System Assembly: A History of Mexico-U.S. Migration", en Beyond Smoke and Mirror. Nueva York: Russell Sage Foundation, 2002. 24-51.

"Nation-State", en United Nations Educational, Scientific and Cultural Organization (UNESCO). En línea disponible en: <http://www.unesco.org/new/en/socialand-human-sciences/themes/international-migration/glossary/nation-state/> [consultado el 25 de octubre de 2018].

Nevins, Joseph. Operation Gatekeeper. The Rise of the "Illegal Alien" and the Making of the U.S.-Mexico Boundary. Nueva York: Routledge, 2002.

Padilla, José IGNACIO. El terreno en disputa es el lenguaje. Madrid: Iberoamericana / Vervuert, 2014.

ShKLOVSKY, VIKTOR. "El arte como artificio", en Teoría de la literatura de los formalistas rusos. Ana María Nethol (trad.). México: Siglo XXI, 1991. 55-70.

YúdicE, GeOrGe, "Producing the Cultural Economy: The Collaborative Art of inSITE", The expediency of Culture: Uses of Culture in the Global Era. Durham / London: Duke University Press, 2003. 287-337.

ISAAC MAGAÑA GCANTÓN

Estudia el doctorado en Romances Languages and Literatures en Harvard University. Entre sus intereses se encuentran la literatura moderna y colonial en Latinoamérica, la cultura material y las vanguardias históricas. 